\title{
REVERSIBLE MYOCARDITIS DUE TO CHRONIC LEAD POISONING IN CHILDHOOD
}

\author{
BY \\ RONALD FREEMAN* \\ From the Royal Alexandra Hospital for Children, Sydney, Australia
}

(RECEIVED FOR PUBLICATION NOVEMBER 26, 1964)

Chronic lead poisoning in childhood, though a relatively uncommon disease, remains a problem in some parts of the world. Between 1948 and 1962, 49 children were treated at the Royal Alexandra Hospital for Children, because of chronic lead poisoning. 48 of the children obtained the lead by ingestion of flaking paint over periods of many months. Encephalopathy was diagnosed in 34 children and 9 of these died. Of the whole group, 21 children have been followed-up adequately and only 8 are known to be well and free of residual effects of the lead poisoning.

Myocardial disease seems to be a rare manifestation of chronic lead poisoning. In children chronic lead poisoning most often presents with a gastrointestinal illness and pallor which may be followed by an acute encephalopathy at any time (Chisolm and Harrison, 1957; Cohen and Ahrens, 1959; Byers, 1959). In Queensland nephropathy has been found commonly to be a late manifestation of the disease (Nye, 1933; Henderson and Inglis, 1957).

There have been few reports of myocarditis due to lead. Hirschfeld (1926) described 4 young men with 'Angina Pectoris Saturnina', the term introduced by Andral (1843) who thought that the lead caused spasm of the coronary vessels. Haubrich (1947) was the first to claim that lead could involve the myocardium directly. He described a 26-year-old woman with lead poisoning who developed what was thought to be an aneurysm of the left atrium due to the lead; 12 years later, however, thoracotomy revealed a malignant thymoma and there was no sign of an aneurysm (Fritze and di Biasi, 1962). Read and Williams (1952) described a man with chronic occupational lead poisoning who complained of chest pain and was found to have an abnormal electrocardiogram. Following treatment of the lead poisoning he lost his chest pain and the electrocardiogram returned to normal. In reviewing the

* Present address: School of Paediatrics, Prince of Wales Hospital, Randwick, New South Wales, Australia. published reports since 1916, Read and Williams could not find a well-substantiated case of myocarditis directly due to lead. Myerson and Eisenhauer (1963) reported atrio-ventricular conduction defects in 2 adults with chronic lead poisoning. The electrocardiograms returned to normal after treatment of the lead poisoning.

Recently chronic myocarditis was found at necropsy in 5 children dying from lead encephalopathy (Kline, 1960), but myocarditis due to lead poisoning, with recovery, has not hitherto been described in childhood.

It is the purpose of this report to record an account of the illness in a girl aged 3 years with chronic lead poisoning associated with myocarditis. When this child presented with lead encephalopathy she was found to have signs of heart failure which was finally attributed to myocarditis directly caused by the lead. Recovery after treatment with sodium calciumedetate (calcium disodium ethylenediaminetetra-acetic acid; $\mathrm{Ca} \mathrm{Na}_{2}$ EDTA) was apparently complete.

\section{Case Report}

P.P., a girl, aged 3 years, was admitted to the Royal Alexandra Hospital for Children on February 6, 1961. She was born in Malta and emigrated with her family to Australia when she was 18 months old. Her early development had been normal and she walked at the age of 12 months and had a fairly good vocabulary on arrival in Australia. She continued to progress well up to the time of the present illness. Her symptoms began 6 weeks before admission to hospital and consisted of anorexia, pallor, vomiting, constipation, irritability, weight loss, and unsteadiness in walking. The vomiting initially occurred 2 to 3 times daily but increased in frequency up to 5 to 6 times each day, becoming projectile and occasionally bile-stained. The other symptoms also became more marked as the illness progressed. Her parents and 2 sibs aged $7 \frac{1}{2}$ years and 3 weeks were in good health and there were no significant illnesses in the family.

Physical Examination on Admission. She was obviously underweight, pale, and extremely irritable, so that 
detailed examination was at first impossible. Following heavy sedation a more complete examination was performed. She weighed $21 \mathrm{lb} .1 \mathrm{oz} .(9 \cdot 6 \mathrm{~kg}$.) and her height was 32 in. $(80 \mathrm{~cm}$.), both below the 10th percentile for age. There was clinical evidence of congestive cardiac failure; the relevant findings were heart rate of 150 a minute, jugular venous pressure $5 \mathrm{~cm}$. above the sternal angle, a gallop rhythm, and the liver palpable $3 \mathrm{~cm}$. below the costal margin. There was no oedema. Her blood pressure was $95 / 50 \mathrm{~mm} . \mathrm{Hg}$ and the femoral pulses were normal. The apex beat could not be localized. A grade 2 pansystolic murmur heard all over the praecordium was maximal in the 4th and 5th left intercostal spaces.

Neurological assessment was difficult but was considered normal apart from possible slight weakness of her legs. The optic fundi were normal. Her head circumference was 18.5 in. $(46 \mathrm{~cm}$.). She was afebrile and the remainder of the physical examination revealed no abnormality.

Investigations. The haemoglobin concentration was 7.6 g. $/ 100 \mathrm{ml}$., the haematocrit $28 \%$, the red cell count $4,850,000 /$ c.mm., reticulocytes $250,000 /$ c.mm. (5\%), total leucocyte count 10,000/c.mm. (neutrophils $63 \%$, lymphocytes $30 \%$, eosinophils $7 \%$ ). Marked coarse basophilic stippling and a moderate number of nucleated red cells were seen on the blood smear, together with some anisocytosis, polychromasia, poikilocytosis, and hypochromia. Platelets were numerous on the blood smear. Sickle-cell and Heinz body preparations were negative. Haemoglobin electrophoresis, using Tris buffer showed slight increase of the $\mathbf{A}_{2}$ fraction; this was also found in the father and thought to be consistent with a thalassaemia trait.

The urine contained traces of sugar and albumin and was normal on microscopy; the specific gravity of early morning specimens exceeded 1,023 on several occasions. The cerebrospinal fluid contained 40 mononuclear cells per c.mm. and $100 \mathrm{mg}$. protein $/ 100 \mathrm{ml}$. Radiographs showed scattered flecks of radio-opaque material in the large bowel, lines of increased density at the metaphyses of the long bones, a normal skull, enlargement of the cardiac silhouette, and some increase in the lung markings (Fig. 1). The electrocardiogram showed flattening of the T wave in leads I, II, AVF, V5, and V6 (Fig. 2).

The blood urea was $27 \mathrm{mg} . / 100 \mathrm{ml}$. Other investigations, including serum electrolytes, serum proteins, and electroencephalography, were normal. No pathogens were isolated from the throat and the tuberculin skin test was negative. The anti-streptolysin- 0 titre was 80 Todd units/ml. (normal up to 200).

Clinical Progress. A presumptive diagnosis of lead intoxication with encephalopathy was made, but the nature of the cardiac lesion was uncertain. Further questioning of the parents revealed that they were living in a house more than 100 years old. The house was in a poor state of repair, paint peeling off the walls both inside and outside. The child had been frequently observed picking the paint off the walls and eating it. A visit to the house substantiated the parents' description and paint scrapings from the walls were examined by the N.S.W.

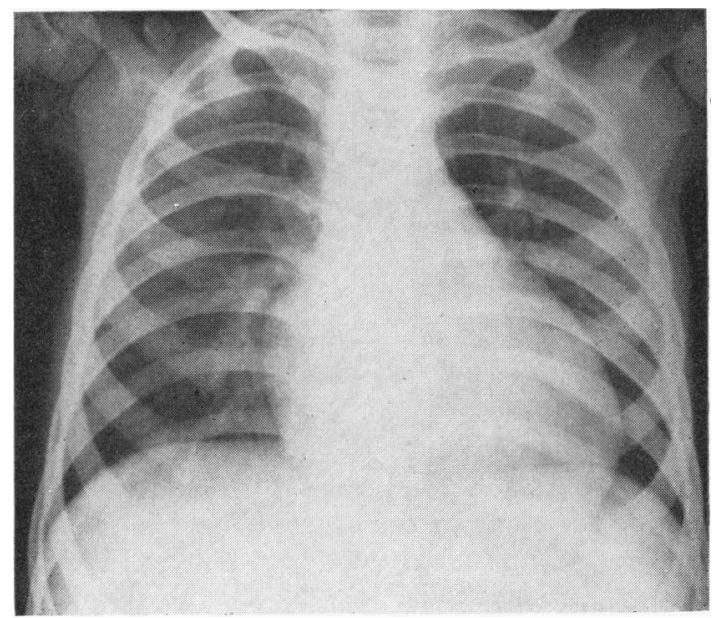

Fig. 1.-Chest radiograph showing enlargement of the heart and increase in lung markings.

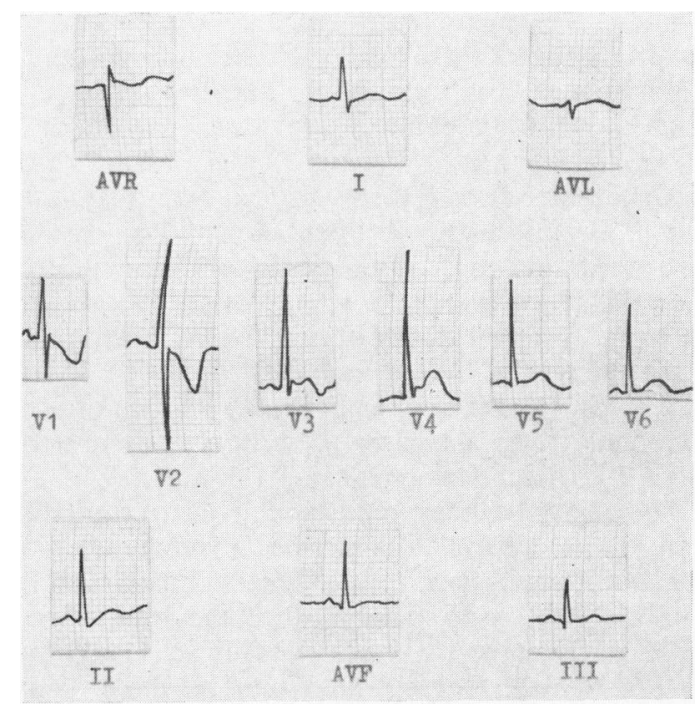

Fig. 2.-Electrocardiogram on February 10, 1961 (shortly after admission to hospital) showing flattened $T$ waves in leads I, II, AVF, V5, and V6.

Government Analyst; all were found to contain lead. Further investigations disclosed marked coproporphyrinuria and the diagnosis of lead poisoning was confirmed by chemical examination of the lead content in the urine; $2 \mathrm{mg}$. of lead was excreted/litre of urine 24 hours (normal up to $0.05 \mathrm{mg}$.).

Removal of the radio-opaque material from the bowel by catharsis and enemata was confirmed radiologically. Sodium calciumedetate, $60 \mathrm{mg}$. $/ \mathrm{kg}$. 24 hours, was given in two divided doses by intravenous infusion and the fluid intake was limited to $1,200 \mathrm{ml}$. daily. She was closely observed for deterioration in her cardiac state, but there 


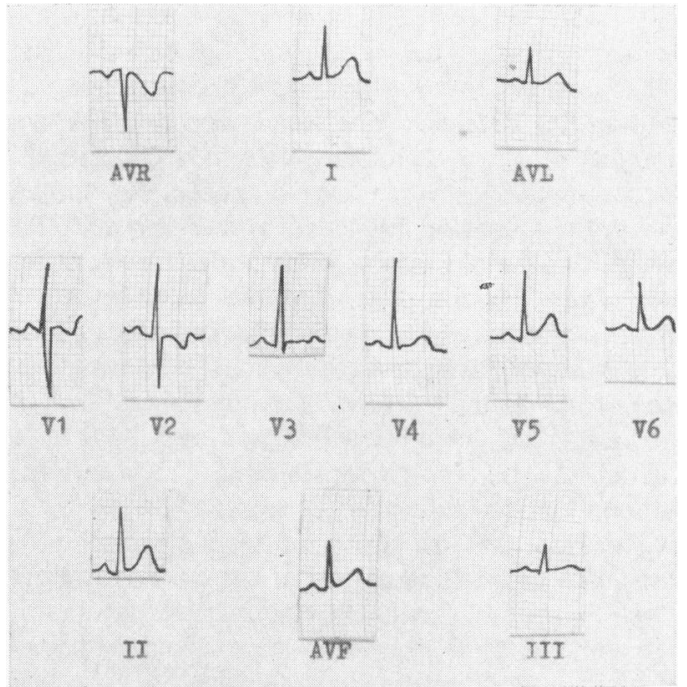

Fig. 3.-Electrocardiogram on March 15, 1961. The T wave voltage is now normal.

was rapid improvement, and after 4 days of sodium calciumedetate therapy signs of congestive cardiac failure had disappeared: the tachycardia had subsided, the jugular venous pressure was not raised, the gallop rhythm had disappeared, and the liver was only just palpable. The praecordial systolic murmur was softer. The electrocardiogram was essentially unchanged, but the chest radiograph showed some decrease in cardiac size and normal lung markings. Her appetite improved, the vomiting ceased, and she was less irritable and withdrawn. 10 days after the course of sodium calciumedetate the copropophyrinuria had disappeared and the urinary lead excretion had fallen to $0.1 \mathrm{mg}$./litre 24 hours.

By March 3, 1961, the patient looked well, the praecordial systolic murmur was no longer heard, the voltage of the $\mathrm{T}$ waves on the electrocardiogram was normal (Fig. 3), and the heart was normal in size, clinically and radiologically. The cytology and protein content of the cerebrospinal fluid had returned to normal.

Despite further clinical improvement the output of lead in the urine remained high and the anaemia persisted. At the end of March 1961 she was given a further course of sodium calciumedetate and a transfusion of $200 \mathrm{ml}$. of packed red cells. Her subsequent progress was excellent; she gained weight and appeared to be a happy normal child. She remained in hospital until the end of May 1961 due to delay in renovating the home; the old paint was removed and replaced by lead-free paint. At the time of discharge from hospital she weighed $28 \mathrm{lb} .8 \mathrm{oz}$. $(13 \mathrm{~kg}$.) and was very well with no signs of cardiac disease. The haemoglobin concentration was $12.5 \mathrm{~g} . / 100 \mathrm{ml}$. and the blood film was normal with no basophilic stippling of the red cells. The urine was free of sugar, albumin, and coproporphyrins, and several estimations of the lead output in the urine were within the normal range.

She was seen at intervals at the out-patient department and on her last visit in January 1962 she was well, weighing $34 \mathrm{lb} .1 \mathrm{oz}$. ( $15 \cdot 5 \mathrm{~kg}$.), and no abnormality could be found on physical examination. Apart from the metaphysial changes in the long bones, all investigations, including blood count, electrocardiogram, chest radiograph, and blood and urine lead levels, were normal. The parents declined further follow-up visits to the hospital as they considered her to be well; a recent home visit confirmed this impression.

\section{Discussion}

A history of eating lead-containing paint, together with gastro-intestinal symptoms, hyperirritability, and weakness of the legs constitute a fairly typical presentation of chronic lead poisoning in childhood. The presence of radio-opaque material in the abdomen, dense lines at the metaphyses of the long bones, anaemia with basophilic stippling of the red cells, and marked coproporphyrinuria support this diagnosis in the patient described. The changes in the cerebrospinal fluid were characteristic of lead encephalopathy (Chisolm and Harrison, 1957) and the greatly increased rate of excretion of lead in the urine provided proof of lead intoxication (Byers, 1959).

The presence of cardiac failure of obscure origin, a pansystolic murmur, and $\mathrm{T}$-wave changes in the electrocardiogram suggested a generalized disease of the myocardium (Brigden, 1957; Goodwin, Gordon, Hollman, and Bishop, 1961). There were no clinical or laboratory findings to suggest that the heart failure might have been due to acute glomerular nephritis or to acute rheumatic fever; a haemolytic streptococcus was not isolated and the anti-streptolysin-0 titre was not raised. There was no evidence of lead nephropathy. The complete disappearance of signs of a cardiac disorder excluded the possibility of congenital heart disease. Severe anaemia, as seen in thalassaemia major, may precipitate cardiac failure, but the anaemia was not severe enough to have been the primary cause of cardiac failure in this patient.

One must admit that it is very difficult, if not impossible, to make a certain diagnosis of leadinduced myocarditis in the living subject, as the possibility of a coincident viral myocarditis cannot be absolutely ruled out. Nevertheless, the diagnosis of lead myocarditis seems to be justified in this child. The concurrence of signs of myocardial insufficiency with those of lead encephalopathy, the rapid disappearance of signs of heart disease during treatment of the lead poisoning with sodium calciumedetate, and evidence from other sources (to be reviewed) leave no doubt as to the toxic effect of lead on the myocardium.

In their monograph on lead poisoning, Aub, Fairhall, Minot, and Reznikoff (1925) state: 
'The heart as might be expected from clinical observation shows nothing remarkable as a result of lead intoxication. ....'

'Most observers believe that the heart undergoes no real change, certainly none due to the direct action of lead.'

Several reports in recent years are in conflict with this statement. Kline (1960) reviewed the necropsy findings in 5 children aged 1 to 2 years, who died from lead encephalopathy. Numerous sections of the heart were examined and chronic myocarditis was found in all 5 children; the changes consisted of cloudy swelling of the myocardial fibres, interstitial fibrosis with a serous exudate, and relatively few inflammatory cells. The myocarditis was considered to be the cause of death of 2 of the children and contributory in the remainder. A review of the clinical findings revealed that all the children had some features of heart failure before death, but these were thought to be due to the encephalopathy. Kline suggested that the serous inflammation, possibly due to intramyocardial vascular changes, was a precursor to fibrosis; he further suggested that vascular changes might be initiated by hypersensitivity, but no vascular changes were demonstrable histologically.

The work of Kośmider and Sroczyński (1961) provides further evidence of the myocardial toxicity of lead. They induced lead intoxication in 10 rabbits by weekly injections of lead acetate and observed the animals for a period of 83 to 180 days. Progressive lead intoxication was confirmed by increasing anaemia, basophilic stippling of the red cells, and rising levels of blood and urine lead. All the rabbits developed abnormal electrocardiographic patterns, of which $T$ wave changes and abnormal QRS complexes were the most common. The electrocardiographic changes were associated with histological changes of the cardiac muscle in the 6 rabbits subsequently subjected to pathological examination. The findings included loss of definition of the muscle structure, degenerative changes of the muscle fibres, and focal fibrosis; inflammatory exudate, however, was seen only in 1 case. They considered that the lead might have a direct effect on the myocardium itself or act indirectly by disturbing the coronary circulation. Species difference and the method of poisoning the rabbits make these changes questionable in relation to man; however, the histological changes do resemble the findings of Kline (1960).

Kośmider and Petelenz (1962) who examined 38 adults over 46 years of age with chronic lead poisoning found organic electrocardiographic changes in $66 \%$, which was 4 times more common than in a control group. Flattening of the $T$ waves and depression of the S-T segment were the most frequent changes, but other findings included short P-R interval, low voltage QRS complexes, and conduction defects. The lead compounds were thought to act by blocking enzymes concerned in cardiac metabolism, leading to subsequent damage. The patient studied by Read and Williams (1952) was a 39-year-old negro male suffering from lead poisoning. He complained of mid-sternal pain, and his electrocardiogram revealed marked depression of the conducting system with inverted $T$ waves in left praecordial leads. 6 days after treatment for lead poisoning his electrocardiogram was essentially normal and he was asymptomatic. Depression of the conduction tissue with toxic changes in the myocardium as the result of lead poisoning was postulated as an explanation of the cardiac findings.

Myerson and Eisenhauer (1963) reported 2 adults with chronic lead poisoning who developed atrioventricular conduction defects; first degree heart block was found in one, and ectopic atrial pacemakers, at times associated with first degree heart block, in the other. The electrocardiogram returned to normal in both patients after treatment with sodium calciumedetate. Increased vagal tone due to the lead was thought to be the mechanism of these conduction defects.

In Queensland, where lead poisoning in children was prevalent in the early part of the century, chronic nephritis in young adults is a common sequel of childhood plumbism (Nye, 1933; Henderson and Inglis, 1957). Hypertension due to lead nephropathy represents an indirect mechanism by which lead might impair the myocardium, and this was the probable cause of the cardiac changes found at necropsy in the 53-year-old man with 'Saturnine Myocardiopathy', reported by Sessa and Guarino (1957).

The mechanism by which lead may impair the heart directly is purely speculative. Lead may be a direct irritant to the myocardium, it may inhibit enzyme systems concerned with cardiac metabolism or it may selectively disturb the coronary circulation. There are very few necropsy reports in which the lead content of the heart has been analysed. Minot and Aub (1924) found $0.3 \mathrm{mg}$. of lead in the heart of an infant who died of lead encephalopathy; the total soft tissue lead exceeded $31 \mathrm{mg}$. It is of interest that relatively small amounts of lead have been found at necropsy in the brains of patients dying from lead encephalopathy; the liver and kidney in most cases were found to contain far higher concentrations (Minot and Aub, 1924; Chisolm and Harrison, 1956; Popoff, Weinberg, and Feigin, 1963). Perhaps certain tissues, such as the brain, are particularly 
susceptible to traces of lead which might disturb the metabolic functions of the organ or result in vascular damage (Popoff et al., 1963). One might postulate that lead causes a similar disturbance of the myocardium, resulting in a serous exudate which subsequently stimulates new growth of connective tissue. There is no evidence that lead impairs the coronary circulation in man, and the absence of vascular changes in the hearts examined by Kline (1960) tends to discount a vascular mechanism. Possibly a metabolic disturbance of the myocardium might result from the direct action of lead, for lead ions have been shown to impair certain enzymes involved in porphyrin metabolism (Watson, Decker, and Lichtman, 1958; Lichtman and Feldman, 1963).

\section{Summary and Conclusions}

The case history of a 3-year-old girl with myocarditis occurring in the presence of chronic lead poisoning and encephalopathy is described. The diagnosis of lead poisoning was made on a history of eating lead-containing paint, and confirmed by laboratory investigations and the response to sodium calciumedetate. Myocarditis was diagnosed by the presence of cardiac failure in association with $T$ wave changes in the electrocardiogram.

The rapid reversal of the clinical and electrocardiographic signs of myocarditis during treatment of the lead poisoning with sodium calciumedetate implies that the lead was responsible for the cardiac changes.

Myocardial impairment in chronic plumbism may result from direct cardio-toxicity of lead, or indirectly from hypertensive changes due to lead nephropathy. The absence of hypertension and of signs of nephropathy exclude the latter mechanism, and infer that the myocarditis was due to the direct action of lead on the heart.

The mechanism by which lead directly affects the myocardium is unknown. There is no evidence of a selective vascular disturbance. Possibly the lead inhibits enzyme systems in the myocardium; this metabolic disturbance might cause an interstitial serous exudate which subsequently stimulates new growth of connective tissue. The complete return to normal of the cardiac status in the child described implies a reversible impairment of myocardial function. Perhaps effective removal of the lead by sodium calciumedetate enabled the exudative reaction to resolve before fibrosis ensued.

The rarity of myocarditis in chronic lead poisoning is unexplained, but it appears to occur in the more seriously poisoned child in whom the features of encephalopathy may overshadow or be thought responsible for the cardiac signs.
The inference to be drawn from this report is that careful assessment and observation with electrocardiographic studies for possible myocardial damage should be part of the management of a patient with chronic lead poisoning. Supportive measures, though not necessary in this child, may be life-saving in children with lead encephalopathy, because undiagnosed myocarditis could be responsible for the death of such a child.

Careful histological examination and chemical estimation of lead content of the heart in patients dying from chronic plumbism may prove of interest. The awareness of myocarditis as a complication of chronic lead poisoning may reveal that cardiac involvement is not as rare as it seems to be.

I thank Dr. S. E. L. Stening, Senior Paediatrician, Royal Alexandra Hospital for Children, for permission to publish this case. I am grateful to Professor John Beveridge and Dr. Graeme Morgan for their helpful criticism in preparing this report.

\section{REFERENCES}

Andral, G. (1843). Medizinische Klinik, Uebersetzt von H. E. Flies, 4th ed., bd. II, teil 2. [Quoted by Read, J. L., and Williams, J. P. (1952). Amer. Heart J., 44, 797.]

Aub, J. C., Fairhall, L. T., Minot, A. S., and Reznikoff, P. (1925). Lead poisoning. Medicine (Baltimore), 4, 1.

Brigden, W. (1957). Uncommon myocardial diseases; the noncoronary cardiomyopathies. Lancet, 2, 1179.

Byers, R. K. (1959). Lead poisoning: Review of the literature and report on 45 cases. Pediatrics, 23, 585.

Chisolm, J. J., Jr., and Harrison, H. E. (1956). The exposure of children to lead. ibid., 18, 943.

(1957). The treatment of acute lead encephalopathy in children. ibid., 19, 2 .

Cohen, G. J., and Ahrens, W. E. (1959). Chronic lead poisoning: review of 7 years' experience at the children's hospital, District of Columbia. J. Pediat., 54, 271.

Fritze, E., and di Biasi, W. (1962). Herzaneurysma nach Bleivergiftung. Arch. Gewerbepath. Gewerbehyg., 19, 340.

Goodwin, J. F., Gordon, H., Hollman, A., and Bishop, M. B. (1961) Clinical aspects of cardiomyopathy. Brit. med. J., 1, 69.

Haubrich, R. (1947). Mitteilung eines Falles von Herzwandaneurysma nach akuter Bleivergiftung. Klin. Wschr., 24-25, 754.

Henderson, D. A., and Inglis, J. A. (1957). The lead content of bone in chronic Bright's disease. Aust. Ann. Med., 6, 145.

Hirschfeld, E. (1926). Angina Pectoris Saturnina. Z. klin. Med., 104, 698.

Kline, T. S. (1960). Myocardial changes in lead poisoning. Amer. J. Dis. Child., $99,48$.

Kośmider, S., and Petelenz, T. (1962). Zmiany elektrokardiograficzne u starszych osob z przewłekym zawodowym zatruciem ołowiem. Pol. Arch. Med. wewnet., 32, 437.

, and Sroczyhski, J. (1961). Zmiany elektrokardiograficzne w przewlekłej doświadczalnej ołowicy u królików. Postepy Hig. Med. dósw., 15, 353 .

Lichtman, H. C., and Feldman, F. (1963). In vitro pyrrole and porphyrine synthesis in lead poisoning and iron deficiency. J. clin. Invest., 42, 830.

Minot, A. S., and Aub, J. C. (1924). Lead studies, V. C. The distribution of lead in the human organism. J. industr. Hyg., 6, 149.

Myerson, R. M., and Eisenhauer, J. H. (1963). Atrioventricular conduction defects in lead poisoning. Amer.J. Cardiol., 11, 409.

Nye, L. J. J. (1933). Chronic Nephritis and Lead Poisoning. Angus and Robertson, Sydney.

Popoff, N., Weinberg, S., and Feigin, I. (1963). Pathologic observations in lead encephalopathy; with special reference to the vascular changes. Neurology (Minneap.), 13, 101.

Read, J. L., and Williams, J. P. (1952). Lead myocarditis; Report of a case. Amer. Heart J., 44, 797.

Sessa, T., and Guarino, A. (1957). Su di un caso di miocardiopatia saturnina: considerazioni diagnostiche e medico-legali. Folia med. (Napoli), 40, 273.

Watson, R. J., Decker, E., and Lichtman, H. C. (1958). Hematologic studies of children with lead poisoning. Pediatrics, 21, 40. 